\title{
Lifelong running reduces oxidative stress and degenerative changes in the testes of mice
}

\author{
Srinivasulu Chigurupati ${ }^{1,3}$, Tae Gen Son ${ }^{1}$, Dong-Hoon Hyun ${ }^{5}$, Justin D Lathia ${ }^{1}$, Mohamed R Mughal ${ }^{1}$, \\ Jason Savell ${ }^{2}$, Shuan C Li ${ }^{2}$, G P C Nagaraju ${ }^{3}$, Sic L Chan ${ }^{3}$, Thiruma V Arumugam ${ }^{1,4}$ and Mark P Mattson ${ }^{1}$ \\ ${ }^{1}$ Laboratory of Neurosciences, National Institute on Aging Intramural Research Program, Baltimore, Maryland 21224, USA \\ ${ }^{2}$ Department of Pathology, Orlando Regional Health Care, Orlando, Florida 32806, USA \\ ${ }^{3}$ Biomolecular Science Center, University of Central Florida, Orlando, Florida 32816, USA \\ ${ }^{4}$ Department of Pharmaceutical Sciences, School of Pharmacy, Texas Tech University Health Sciences Center, Amarillo, Texas 79106, USA \\ ${ }^{5}$ Division of Life and Pharmaceutical Sciences, Ewha Woman's University, Seoul 120-750, South Korea \\ (Correspondence should be addressed to M P Mattson at Laboratory of Neurosciences, Biomedical Research Center, 5 th floor, 251 Bayview Boulevard, \\ Baltimore, Maryland 21224-6825, USA; Email: mattsonm@grc.nia.nih.gov)
}

\begin{abstract}
Regular exercise can counteract the adverse effects of aging on the musculoskeletal and cardiovascular systems. In males, the normal aging process is associated with reductions in testosterone production and impaired spermatogenesis, but the underlying mechanisms and their potential modification by exercise are unknown. Here, we report that lifelong regular exercise (running) protects the testes against the adverse effects of advancing age, and that this effect of running is associated with decreased amounts of oxidative damage to proteins, lipids, and DNA in spermatogenic and Leydig cells. Six-month-old male mice were divided into a sedentary group and a group that ran an average of $1.75 \mathrm{~km} /$ day, until the mice reached the age of 20 months. Seminiferous tubules
\end{abstract}

of runners exhibited a full complement of cells at different stages of the spermatogenic process and a clear central lumen with large numbers of spermatozoa, in contrast to sedentary mice that exhibited disorganized spermatogenic cells and lacked spermatocytes in a central lumen. Levels of protein carbonyls, nitrotyrosine, lipid peroxidation products, and oxidatively modified DNA were significantly greater in spermatogenic and Leydig cells of sedentary mice compared with runners. These findings suggest that lifelong regular exercise suppresses aging of testes by a mechanism that involves reduced oxidative damage to spermatogenic and Leydig cells.

Journal of Endocrinology (2008) 199, 333-341

\section{Introduction}

Although the aging process is complex and the underlying mechanisms poorly understood, there is considerable evidence that cumulative oxidative damage to proteins, lipids, and DNA is involved (Sohal \& Weindruch 1996, Mattson \& Liu 2002, Sanz et al. 2006, Liu et al. 2008). Major reactive oxygen species (ROS) implicated in age-related tissue dysfunction and damage include superoxide anion radical, hydrogen peroxide, hydroxyl radical, and nitric oxide and peroxynitrite (Cadenas \& Davies 2000, Drew \& Leeuwenburgh 2002). These ROS can cause damage to membranes (lipid peroxidation) and molecular modifications of proteins including protein carbonyl formation, nitration, and covalent modification by lipid aldehydes. Physical exercise is used for different purposes including the enhancement of competitive performance and disease prevention. Regular physical activity may reduce the risk of type 2 diabetes, cardiovascular diseases, and some cancers (Dugan 2007). During exercise, there are increased metabolic demands on the musculoskeletal and cardiovascular systems, and a concomitant increase in the production of ROS. However, the cells respond to the oxidative stress by increasing the production of antioxidant enzymes and other defense mechanisms (Banerjee et al. 2003, Jackson et al. 2004). Such adaptive responses to the cellular stress associated with exercise may contribute to the beneficial effects of exercise on health.

As with other organ systems, the male reproductive organs suffer functional decline with aging characterized by reduced serum levels of testosterone and reduced production of sperm (Vermeulen 1991, Barnes et al. 1998, Harman et al. 2001, Snyder 2001, Matsumoto 2002).

Morphological characteristics of aging testes include a reduced number of type-A dark spermatogonia, and increased occurrence of multinucleated spermatogonia, megalospermatocytes, and giant spermatids (Schulze \& Schulze 1981, Gosden et al. 1982, Almahbobi et al. 1988). Sertoli cells accumulate cytoplasmic lipid droplets and are reduced in number, as are the Leydig cells during aging (Johnson 1986). The causes of cellular dysfunction in the testes during aging 
are unknown, but oxidative stress is implicated (Cao et al. 2004). Intense exercise has been reported to result in decreased production of testosterone and decreased spermatogenesis (Cumming et al. 1989, Hackney et al. 2003, Manna et al. 2003). However, the pro-oxidative effect of acute exercise was attenuated in rats that had been exercised regularly on a treadmill for 8 weeks prior to the acute exhaustive exercise (Aksoy et al. 2006). Although regular exercise is associated with improved health outcomes in humans, the effects of long-term regular exercise on the testes are unknown. Here, we report that lifelong running protects the testes against age-related cytological alteration and oxidative stress in mice.

\section{Materials and Methods}

\section{Animals and wheel running}

Six-month-old male C57BL/6 mice were divided into a sedentary control group $(n=28)$ and a running group $(n=18)$. The running group ran an average of $1.75 \mathrm{~km} /$ day on a home cage running wheel (Columbus Instruments, Columbus, OH, USA) for 14 months. The wheel itself clips to the wire lid inside the cage and contains an embedded magnetic indicator. The rotation detector attaches to the lip of the plastic dome outside of the cage and the hall-effect detector counts the number of rotations of the wheel. Detectors plug into a common interface that connects to a computer via RS232. Wheel rotations are converted into $\mathrm{km}$ automatically by software. The cages of the sedentary group contained a locked running wheel. The mice were maintained for 14 months with continuous access to water and food, in a $12 \mathrm{~h}$ light:12 $\mathrm{h}$ darkness cycle.

\section{Quantification of Sertoli and Leydig cell numbers}

Quantitative assessment of Sertoli and Leydig cell numbers was made to obtain relative differences between sedentary versus runner mice. Estimates were obtained by randomly superimposing a forbidden line unbiased counting frame (Myers et al. 2005) on enlarged photomicrographs of stained tissues, where the nuclei of Sertoli cells could be unequivocally identified by their characteristic location and appearance (e.g., tripartite nucleolus, (Howard \& Reed 2005)). Using this counting frame, the numbers of nuclear profiles per unit area of testis were counted. Sertoli cells were identified primarily based on nuclear morphology and based on their proximity to basement membrane. The morphological features we used to identify these cells were irregularly shaped, folded nuclear membranes and the presence of a prominent nucleolus. Cytosolic features such as lipid vacuoles and granular eosinophilic material were also considered. Leydig cells are identified based on location (interstitium) and histological features including a round vesicular nucleus with one or two eccentrically located nucleoli along with an abundant cytoplasm with lipid droplets and lipofuscin pigment.

\section{Serum testosterone measurement}

Mice were anesthetized with isoflurane and immediately dissected to access the heart. Blood was collected and centrifuged at $10000 \mathrm{~g}$ for $10 \mathrm{~min}$ at $4{ }^{\circ} \mathrm{C}$ to isolate the serum. If the serum was not used immediately, it was kept at $-20{ }^{\circ} \mathrm{C}$ until further analysis. Serum testosterone concentrations from individual mice were measured by National Hormone \& Peptide Program Harbor-UCLA Medical Center, Torrance, CA, USA by RIA after ether extraction according to published methodology (Resko et al. 1973). The sensitivity of the assay was $7 \cdot 8 \mathrm{pg}$ per tube, the inter-assay variation was $8 \%$, and the intra-assay variation was $4 \cdot 3 \%$.

\section{Oxidative stress markers}

Testes were homogenized in T-PER Reagent according to the manufacturer's instructions. (Pierce, Rockford, IL, USA. Cat \# 78510) Samples were centrifuged to pellet tissue debris. For each assay, $40 \mu \mathrm{g}$ protein were used. An Amplex Red Hydrogen peroxide/Peroxidase Assay Kit (Molecular Probes, Eugene, OR, USA) was used to measure $\mathrm{H}_{2} \mathrm{O}_{2}$ levels using the protocol provided with the kit. Briefly, $5 \mu \mathrm{M}$ Amplex Red and $15 \mu \mathrm{g} / \mathrm{ml}$ horseradish peroxidase (3.75 Units) were included in the incubations. $\mathrm{H}_{2} \mathrm{O}_{2}$ was detected by the formation of the fluorescent Amplex Red oxidation product resorufin using excitation and emission wavelengths of 563 and $587 \mathrm{~nm}$ respectively. Lipid peroxidation levels were assessed using an 8-Isoprostane Assay Kit (OxisResearch, Portland, OR, USA). Briefly, protein fractions $(100 \mu \mathrm{l})$ were added to a 96-well plate and incubated with $100 \mu$ of horseradish peroxidase-conjugated antibody at room temperature for $1 \mathrm{~h}, 200 \mu \mathrm{l}$ of substrate were added to each well, and after a $30 \mathrm{~min}$ incubation the reaction was stopped by adding $50 \mu \mathrm{l}$ of $3 \mathrm{M}$ sulfuric acid and the absorbance was read at $450 \mathrm{~nm}$. Protein carbonyl content was determined as described previously (Lyras et al. 1996), except that the final protein pellets were dissolved in $1 \mathrm{ml}$ of $6 \mathrm{M}$ guanidinium hydrochloride. Carbonyl content was calculated as nmol/mg of protein. Measurement of protein-bound nitrotyrosine content was performed using a Nitrotyrosine Assay Kit (OxisResearch) using the protocol provided with the kit.

\section{Quantification of gene expression by real-time PCR}

Total RNA was isolated from the testes using a Tri kit (Sigma). First-strand cDNA was generated with random hexamers as primers using AMV and M-MLV reverse transcriptase $\mathrm{H}$ plus (ABgene, Epsom, United Kingdom), according to the manufacturer's recommendations. To compare mRNA levels in different samples, the relative abundance of specific mRNAs was normalized against the glyceraldehyde 3 phosphate mRNA level. Raw data were processed by 
means of the comparative $C_{\mathrm{t}}$ method by formula $2^{-\Delta \Delta C_{\mathrm{t}}}$. For RT-PCR, gene-specific forward and reverse primers (Table 1) were designed based on sequences obtained from GenBank. The PCR mixture consisted of $0.5 \mathrm{ng}$ of a cDNA template for gene-specific cDNA amplification or Gly-3-P amplification, respectively, for $625 \mathrm{nM}$ of each primer, and $10 \mu \mathrm{l}$ of $2 \times$ SYBR green Master mix (Applied Biosystems, Foster City, CA, USA) in a final volume of $20 \mu$ l. Amplification was carried out under the following conditions: initial denaturation at $95^{\circ} \mathrm{C}$ for $10 \mathrm{~min}$, followed by 40 cycles of denaturation at $95^{\circ} \mathrm{C}$, and annealing followed by extension at $60^{\circ} \mathrm{C}$. Amplification of gene-specific cDNA and Gly-3-P cDNAs of the same sample was performed simultaneously in separate tubes in duplicate. Each plate contained repeated reference samples, and the pooled results for all plates were analyzed with ABI Prism 7000 Sequence Detection System software version 1.1 (PE Applied Biosystems). Raw data for each plate were entered into a Microsoft Excel spreadsheet and the relative expression values for all gene-specific samples were calculated manually to confirm the results.

\section{Histology}

Testes collected at the end of the experiment were Bouin fixed and paraffin embedded. Sections $(5 \mu \mathrm{m})$ were stained with hematoxylin and eosin and viewed by transmitted light microscopy. Histopathological damage was assessed by examination of 100 seminiferous tubule cross sections per testis.

\section{Immunoblot analysis}

After tissue homogenization, tissue lysates were obtained by resuspending tissue in RIPA buffer $(50 \mathrm{mM}$ Tris- $\mathrm{HCl}, 0 \cdot 5 \%$ Triton X-100, 0.25\% Na deoxycholate, $0 \cdot 1 \%$ SDS, $150 \mathrm{mM}$ $\mathrm{NaCl}, 1 \mathrm{mM}$ EDTA, and $5 \mathrm{mM} \mathrm{MgCl} 2$ ) containing a 1:1000 dilution of protease inhibitor mixture (Sigma-Aldrich). A clear supernatant was obtained by centrifugation of lysates at $17000 \mathrm{~g}$ for $10 \mathrm{~min}$. Protein content was determined using a BCA Protein Assay Kit (Pierce). Proteins $(50 \mu \mathrm{g})$ were separated by SDS-PAGE (8-12\%) and transferred to a nitrocellulose membrane. Primary antibodies included: rabbit polyclonal

Table 1 Gene specific primers for RT-PCR

Primer sequence from $5^{\prime} \rightarrow 3^{\prime}$

$\begin{array}{ll}\text { Primer name } & \\ \text { SOD1 } \mathrm{F} & \text { GATGAAGAGAGGCATGTTGGAGA } \\ \text { SOD1 R } & \text { ATGGTTTGAGGGTAGCAGATGAG } \\ \text { SOD2 } \mathrm{F} & \text { GGCCTACGTGAACAATCTCAAC } \\ \text { SOD2 R } & \text { GACCTTGCTCCTTATTGAAGCC } \\ \text { GPX1 F } & \text { CTACACCGAGATGAACGATCTG } \\ \text { GPX1 R } & \text { CTCAAAGTTCCAGGCAATGTCG } \\ \text { GPX4 F } & \text { TTTCGTGTGCATCGTCACCA } \\ \text { GPX4 R } & \text { CACGCAGCCGTTCTTATCAATG } \\ \text { GAPDH F } & \text { TGGAGTCTACTGGTGTCTTCAC } \\ \text { GAPDH R } & \text { GTGGATGCAGGGATGATGTTCT }\end{array}$

www.endocrinology-journals.org against superoxide dismutase (SOD1), rabbit polyclonal against hemeoxygenase-1 (HO1), and goat polyclonal against glutathione peroxidase-1 (GPX1; Santa Cruz Biotechnology Inc., Santa Cruz, CA, USA); anti-phospho-histone H2AFX (Ser139) and clone JBW 301 (Upstate, Temecula, CA, USA); rabbit polyclonal against 4-hydroxy-2-nonenal (HNE)-Michael adducts, reduced rabbit pAb (Calbiochem, EMD Chemicals Inc. San Diego, CA, USA); and a mouse monoclonal against $\beta$-actin (Sigma-Aldrich).

\section{Immunohistochemistry}

Briefly, sections (5 $\mu \mathrm{m}$ thick) of paraffin-embedded mice testes were deparaffinized before being exposed to citrate buffer $(0 \cdot 01 \mathrm{M}, \mathrm{pH} 6 \cdot 0)$ heated in a microwave for $3 \mathrm{~min}$. The sections were treated with $0.3 \%$ hydrogen peroxide in methyl alcohol for $20 \mathrm{~min}$ to block endogenous peroxidase activity. After washing thrice in PBS, the sections were incubated with appropriate blocking serum before being incubated over night at $4{ }^{\circ} \mathrm{C}$ with one of the following primary antisera: mouse anti-nitrotyrosine antibody (Zymed Laboratories, South San Francisco, CA, USA), monoclonal antibody against 8-hydroxy-2'-deoxyguanosine (Genox Corporation, Baltimore, MD, USA), and anti-HNE-Michael adducts, reduced rabbit pAb (Calbiochem, EMD Chemicals Inc. 92121). After washing thrice in PBS, the appropriate biotinylated secondary antibody and avidin-biotin peroxidase complex (Vector Elite Kit; Vector, Burlingame, CA, USA) were added sequentially. The peroxidase reaction was developed using a peroxidase substrate kit (diaminobenzidine DAB, SK-4100; Vector). Before being mounted, the sections were counterstained with hematoxylin. For controls, each of the primary antisera was omitted from some sections.

\section{Quantification of immunohistochemistry by the positive pixel count algorithm}

The immune complex was visualized with $\mathrm{DAB}$ and counterstained with hematoxylene and positive-stained cells were detected in the presence and absence of distinct staining by using positive pixel count algorithm that quantifies the amount of a specific stain in a scanner slide image using tissue microarray software from Aperio Technologies Inc., Vista, CA, USA (Liu et al. 2008). Briefly, brown color of DAB is specified (range of hues and saturation) with three intensity ranges (weak, positive, and strong) for pixels that satisfy the color specification; the algorithm counts the number and intensity sum in each intensity range, along with three additional quantities: average intensity, ratio of strong/total number, and average intensity of weak positive pixels. The algorithm has been set with default input parameters when first selected - these inputs have been pre-configured for brown color quantification in the three intensity ranges (220 $175,175-100$, and 100-0). Pixels that are stained, but do not fall into the positive-color specification, are considered negative stained pixels - these pixels are counted as well, so 
that the fraction of positive to total stained pixels is determined. The algorithm is applied to an image by using ImageScope. This program allows to select an image region of analysis, specify the input parameters, run the algorithm, and view/save the algorithm results. When using the ImageScope program, a pseudo-color markup image is also shown as an algorithm result. The markup image allows the user to confirm that specified inputs are measuring the desired color and intensity ranges. Once a set of algorithm inputs has been confirmed, the settings can be saved in a macro file for subsequent repeated use.

\section{Results}

Lifelong running protects the testes against age-related histological changes

All mice were housed in identical cages in the same room within the animal facility, and were provided food and water ad libitum. When the mice reached 20 months of age we collected their reproductive organs (excluding the epididymis). Gross examination revealed enlarged seminal vesicles and testes in the sedentary animals compared with runners

A

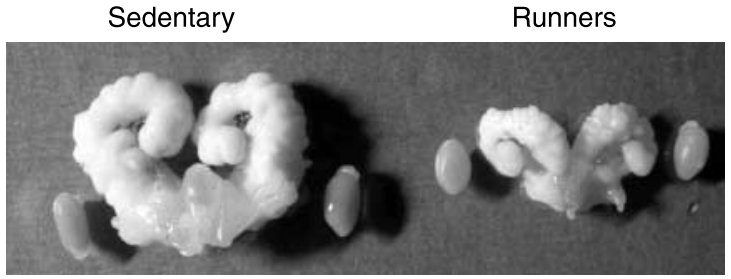

B
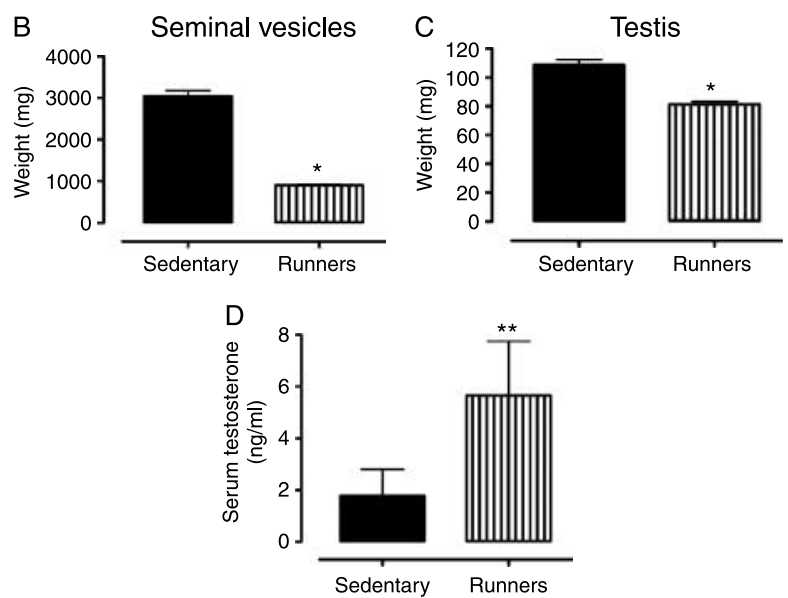

Figure 1 Aged sedentary mice exhibit enlarged seminal vesicles and testes compared with lifelong runners. (A) Photographs of the seminal vesicles and testes of a representative sedentary mouse (left) and lifelong runner mouse (right). (B and $\mathrm{C}$ ) Weights of seminal vesicles $(B)$ and testes $(C)$ of sedentary mice and runners. Values are mean \pm S.E.M. ( $n=6$ mice per group), $* P<0 \cdot 001$. (D) Serum testosterone levels. Values are mean \pm s.E.M. $(n=6$ mice per group), $* * P<0 \cdot 001$
(Fig. 1A). Weights of seminal vesicles (Fig. 1B) and testes (Fig. 1C) of sedentary mice were significantly greater than those of runners. The serum testosterone level of runners was significantly greater than that of sedentary animals (Fig. 1D).

To investigate possible differences in the cellular organization of testes, they were Bouin fixed and paraffin embedded, and then sections were stained with hematoxylin and eosin. There were markedly fewer spermatogonia in the seminiferous tubules of sedentary mice compared with runners (Fig. 2A). High-magnification micrographs revealed cells at different stages of the spermatogenic process, which were clearly visible in single sections from runners, compared with sedentary mice (Fig. 2B); at different stages of spermatogonia, spermatids were abundant in seminiferous tubules from runners. Testes from sedentary mice exhibited focal and diffuse areas of sclerosis, which were not evident in runners (Fig. 2). Non-spermatogenic Sertoli cells, which support and nourish spermatozoa, were significantly more in the seminiferous tubules of runners, but were sparse in sedentary mice (Fig. 2B). These cells divided the seminiferous epithelium into basal and adluminal compartments in runners, a compartmentalization that was lacking in the testes from sedentary mice. At higher magnification, the interstitial supporting tissue between the seminiferous tubules showed a significant reduction in Leydig cell number and size in sedentary mice compared with runners (Fig. 2C and D). In runners, Leydig cells were present as single cells and cell clusters.

Running decreases levels of lipid peroxidation and oxidative stress in the testes

Hydrogen peroxide is one of the ROS secreted by macrophages that are seen closely aligned with Leydig cells in the testicular interstitium (Gautam et al. 2006). We first measured levels of $\mathrm{H}_{2} \mathrm{O}_{2}$ in the testes and found that the amount of $\mathrm{H}_{2} \mathrm{O}_{2}$ was significantly less in runners compared with sedentary mice (Fig. 3A). The levels of 8 -isoprostane, a marker of lipid peroxidation (Morrow 2006, Johnson et al. 2007), were also significantly less in the testes of runners compared with sedentary mice (Fig. 3B). Levels of nitrotyrosine (a marker of reactive nitrogen species) and protein carbonyl levels (a biomarker of protein oxidation; Beal 2002) were significantly lower in the testes of runners compared with sedentary mice (Fig. 3C and D). To assess the effect of lifelong running on oxidative stress-responsive enzymes in the testes, we measured the levels of SOD1, HO1, GPX, and phosphorylated histone $\gamma$-H2AFX in the testes from both groups of mice. Immunoblot analysis showed that HO1, GPX, and $\gamma$-H2AFX were significantly reduced in the testes from runners compared with sedentary mice (Fig. 3E and F). We also measured the level of the lipid peroxidation product $\mathrm{HNE}$, a toxic aldehyde implicated in various age-related diseases (Keller \& Mattson 1998), in the testes from both groups. HNE levels were significantly lower in the testes from runners compared with sedentary mice (Fig. 3G and $\mathrm{H}$ ). In order to see the effect of running on 
mRNA levels of the major antioxidant enzymes (SOD1, SOD2, GPX1, and GPX4), we performed real-time PCR analysis. Our data showed that SOD1, SOD2, and GPX4 mRNA levels were significantly low in runners compared with sedentary animals (Fig. 3I).

In order to gain insight into which cell types within the testes suffer oxidative stress as a result of a sedentary lifestyle, we performed immunohistochemical staining of tissue sections of testes from runners and sedentary mice using antibodies against nitrotyrosine, $\gamma-\mathrm{H} 2 \mathrm{AFX}$, and 8-hydroxy2 -deoxyguanosine (a marker of oxidative DNA damage; Yarborough et al. 1996). As expected, overall levels of nitrotyrosine immunoreactivity were significantly greater in
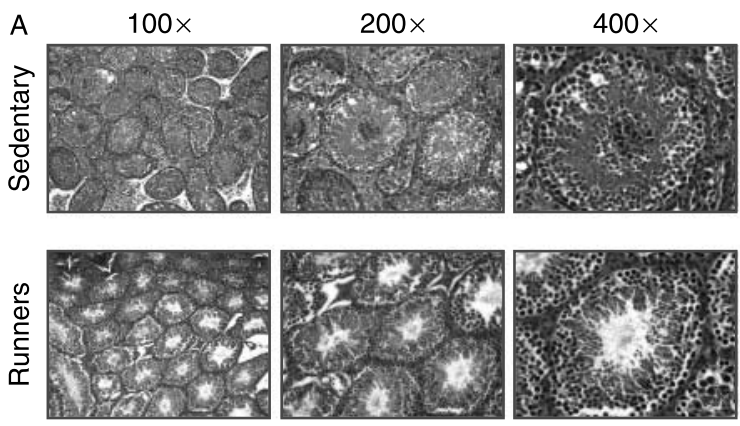

B

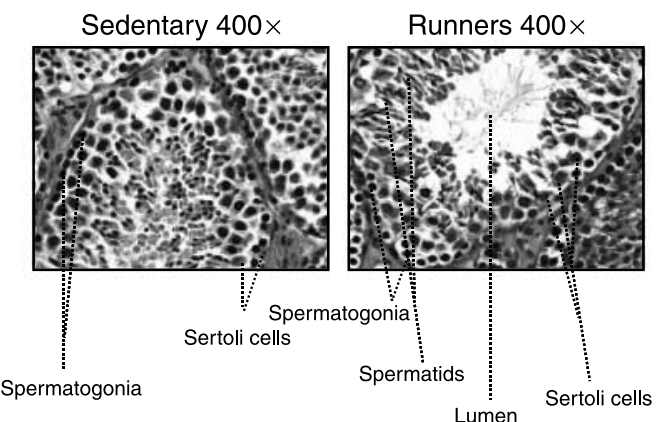

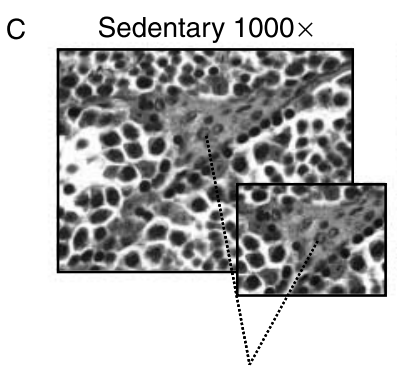

Leydig cells

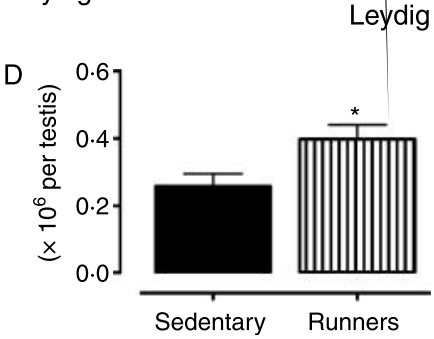

sections of testes from sedentary mice, compared with runners (Fig. 4A and B). Leydig cells and spermatogonia exhibited the highest levels of nitrotryosine immunoreactivity (Fig. 4A), suggesting that these cell types were subjected to particularly high levels of nitrosative stress in sedentary mice. The levels of 8-hydroxy-2'-deoxyguanosine immunoreactivity were significantly greater in sections of testes from sedentary mice, compared with runners (Fig. 4C and D), with all cell types within the seminiferous tubules, as well as Leydig cells, exhibiting robust immunoreactivity (Fig. 4C). The levels of $\gamma$-H2AFX immunoreactivity were significantly greater in sections of testes from sedentary mice, compared with runners (Fig. 4E and F).

Leydig cells and all cell types within the seminiferous tubules exhibited robust $\gamma$-H2AFX immunoreactivity in the testes of sedentary mice; only spermatogonia exhibited strong $\gamma$-H2AFX immunoreactivity in the testes of runners (Fig. 4E).

\section{Discussion}

Degenerative and sclerotic changes were prominent in the testes of old sedentary mice, but were absent in the testes of old lifelong runners. Associated with reduced levels of circulating testosterone (Vermeulen 1991, Harman et al. 2001, Matsumoto 2002) and sperm production in aging males are reductions in the number of type A dark spermatogonia, Sertoli and Leydig cells, and increased numbers of multinucleated spermatogonia, megalospermatocytes, giant spermatids, and multilayered spermatogonia (Horn et al. 1996, Sampson et al. 2007). Consistent with the latter findings, we observed very low numbers of type A spermatogonia and spermatocytes in the seminiferous tubules of aged sedentary mice. By contrast, the seminiferous tubules of age-matched lifelong runners exhibited cytological features similar to those of young males including a well-organized stratification of the spermatogenic cells and luminal sperm. Sertoli cells provide nutritive and tropic support for spermatogenic cells (Griswold

Figure 2 Testes of old lifelong runners exhibit preserved cellular composition and integrity compared with sedentary mice. (A). Micrographs of H\&E-stained sections of testes from sedentary mice and runners shown at three different magnifications. The micrographs illustrate transverse sections through seminiferous tubules. Loss of spermatogonia was prominent in sedentary mice, whereas cells at all stages of the spermatogenic process are clearly visible in runners. (B) High magnification micrographs reveal focal and diffuse areas of sclerosis, and a sparsity of Sertoli cells in seminiferous tubules of sedentary mice. By contrast, cells at different stages of spermatogenesis, as well as Sertoli cells, are evident and organized in the normal outside-in progression within the seminiferous tubules of runners. Clear lumen, numerous spermatids, and more number of Sertoli cells are also a hallmark in runners. (C) At higher magnification, interstitial supporting tissue between the seminiferous tubules reveals a reduction in Leydig cell number and size in sedentary mice compared with runners. (D) Leydig cell number in sedentary mice compared with runners. Values are mean \pm S.E.M. ( $n=6$ mice per group), $* P<0 \cdot 001$. 
1998), and a decrease in Sertoli cell number with aging is correlated with a decreased sperm count (Neaves et al. 1984, Paniagua et al. 1987). Our study found that Sertoli cells are abundant in seminiferous tubules of runners, whereas they are diminished in sedentary aged animals. Similarly, Leydig cell
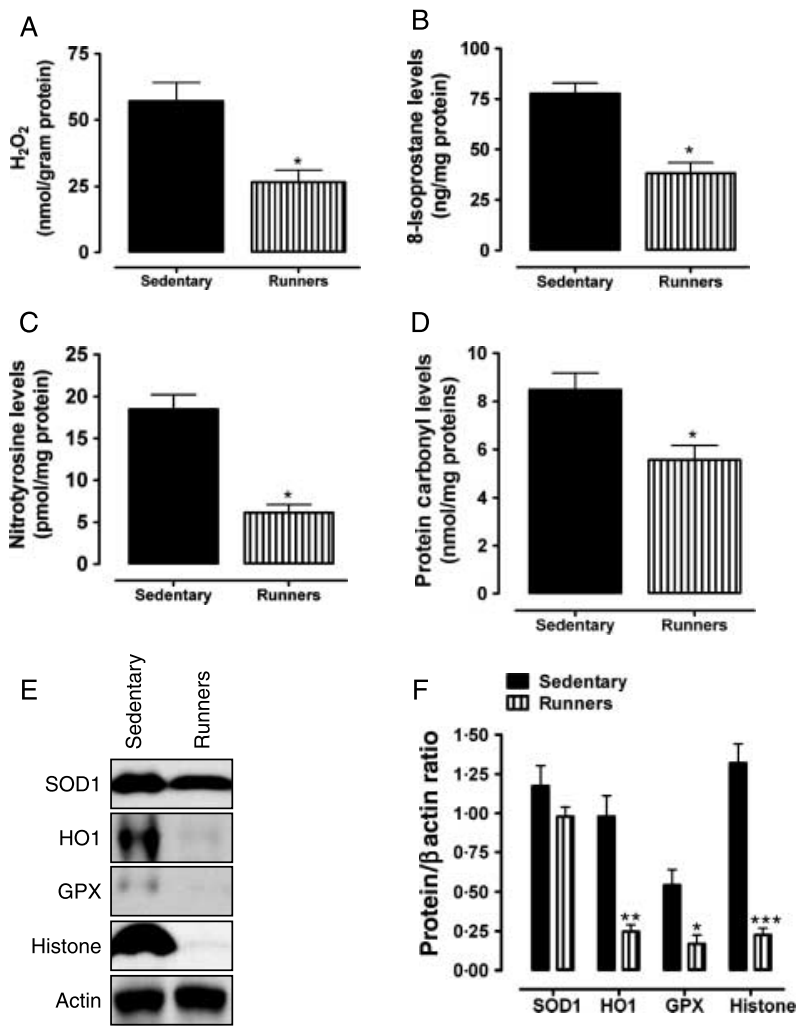

G
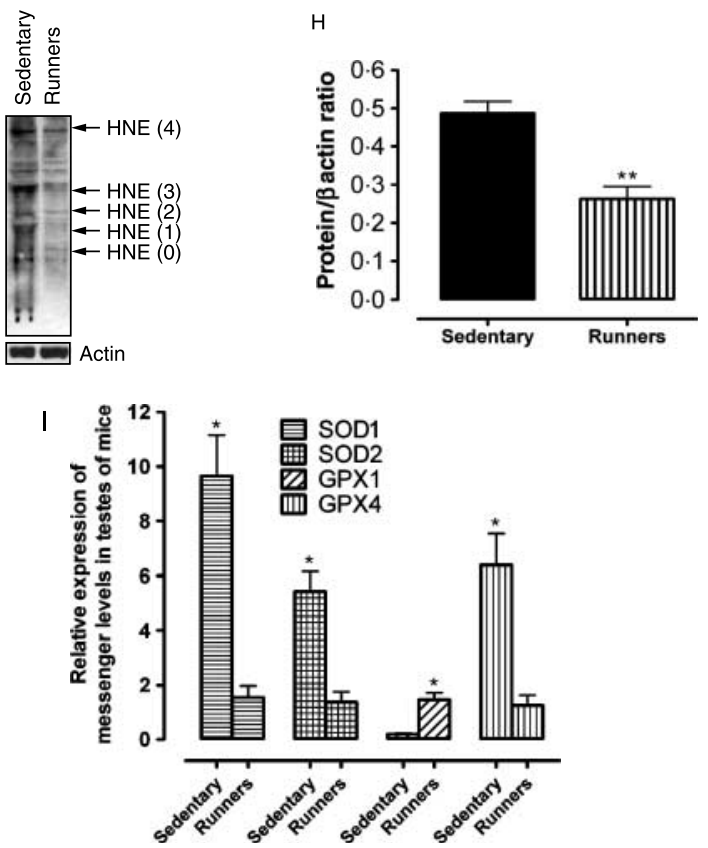

number was lower in the testes of mice in the sedentary group compared with runners.

Our findings are consistent with a major role for accumulated free radical damage in the disruption of spermatogenic process during aging. Levels of $\mathrm{H}_{2} \mathrm{O}_{2}$, protein carbonyls, nitrotyrosine, lipid peroxidation products, and oxidatively modified DNA were all present in relatively high amounts in the testes of sedentary mice compared with runners. Immunostaining of testes tissue sections with antibodies against nitrotyrosine, 8-hydroxy- $2^{\prime}$-deoxyguanosine, and $\gamma$-H2AFX indicated high levels of oxidative damage to proteins and DNA in spermatogonia and Leydig cells in sedentary mice compared with runners. These findings suggest that lifelong regular exercise can counteract age-related oxidative damage to cells critical for sperm and testosterone production. The testicular cells of old sedentary mice may respond to the oxidative stress by upregulating their production of antioxidant enzymes as indicated by higher levels of SOD1, HO1, and GPX in the testes of sedentary mice compared with runners. It is also possible that the mild stress associated with running may trigger androgen production by the adrenal gland, thereby contributing to increased circulating levels of testosterone.

The specific mechanism(s) by which running protects the testes against aging remains to be established. However, previous studies of the effects of exercise on other tissues suggest several possibilities. Exercise may increase the resistance of cells to stress by activating adaptive stress response pathways including those involving transcription factors such as nuclear factor (NF)- $\kappa \mathrm{B}$ and mitogen-activated protein kinases, resulting in increased expression of genes that encode cytoprotective proteins such as heat shock proteins (HSP), phase 2 enzymes, and antioxidant enzymes (Ji 2007, Marini et al. 2007, Quindry et al. 2007). Indeed, exercise training increases SOD1 and (HSP)-72 content in the myocardium as well as in other organs (Yamashita et al. 1999, Starnes \& Taylor 2007). In proliferative tissues prone to cancer, exercise can upregulate the expression of proteins that induce apoptosis of damaged (potentially cancerous) cells (Campbell et al. 2007). Regular exercise is believed to reduce the risk of several types of cancer including those of the colon (Slattery 2004), prostate gland (Giovannucci et al. 2005) and breast

Figure 3 Lifelong running results in reduced levels of lipid peroxidation, and protein carbonylation and nitration in the testes. Levels of $\mathrm{H}_{2} \mathrm{O}_{2}(A)$, isoprostanes (B), nitrotyrosine $(C)$, and protein carbonyls (D) were measured in testicular samples of sedentary mice and runners. Values are mean \pm S.E.M. ( $n=6$ mice per group), $* P<0 \cdot 01$. Proteins isolated from the testes of sedentary mice and runners were used to measure the levels of antioxidant enzymes (SOD, Cu/Zn-superoxide dismutase; HO1, heme oxygenase; GPX, glutathione peroxidase) and $\gamma-\mathrm{H} 2 \mathrm{AFX}$ ( $\mathrm{E}$ and $\mathrm{F}$ ) and proteins modified by the lipid peroxidation product 4-hydroxynonenal $(\mathrm{HNE})(\mathrm{G}$ and $\mathrm{H})$. Values are mean \pm s.E.M. ( $n=6$ mice per group), ${ }^{*} P<0 \cdot 05$. ${ }^{* * *} P<0 \cdot 001,{ }^{* *} P<0 \cdot 01$. (I) mRNA levels of $S O D 1$, $S O D 2, G P X 1$, and GPX4 in sedentary mice compared with runners. Values are mean \pm S.E.M. $(n=6$ mice per group), $* P<0 \cdot 001$. 
A

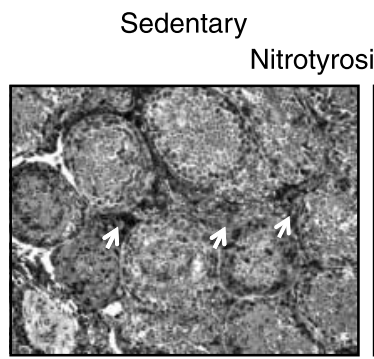

C

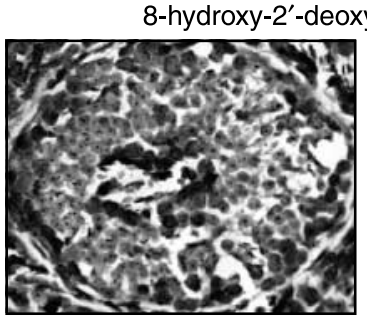

E

20X

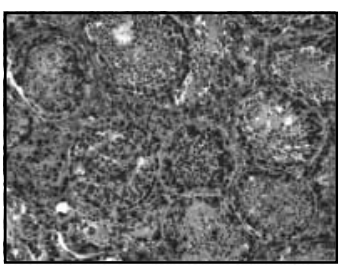

$40 \mathrm{X}$

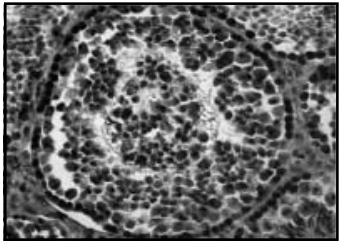

Runners
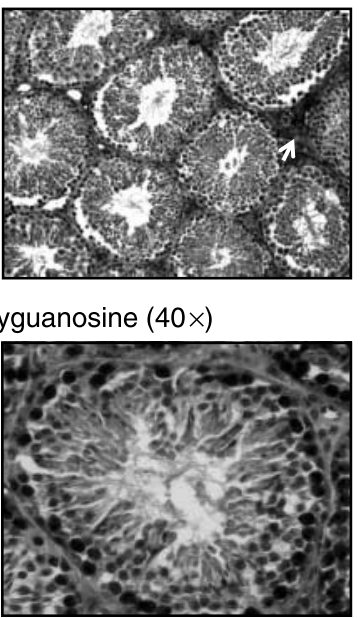

Runners
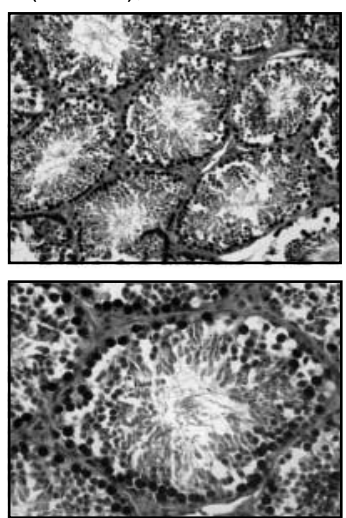

B

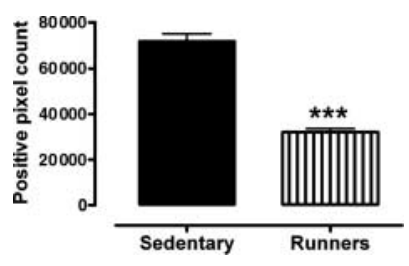

$\mathrm{D}$

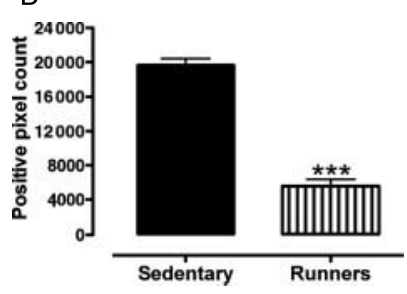

$\mathrm{F}$

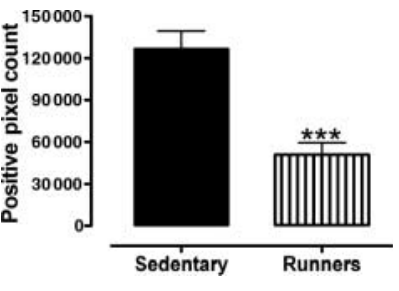

Figure 4 Lifelong running results in reduced levels of nitrotyrosine (A and B), 8-OHdG (C and D) and $\gamma-\mathrm{H} 2 \mathrm{AFX}\left(\mathrm{E}\right.$ and $\mathrm{F}$ ) immunoreactivities in testicular cells, ${ }^{* * *} P<0 \cdot 001$. Arrows indicate that oxidation marker nitrotyrosine are present in Leydig cells.

cancer (Monninkhof et al. 2007). Results of epidemiological studies have also suggested a protective effect of exercise against testicular cancer. The beneficial effects of exercise in reducing oxidative damage and preserving the cellular normalcy in the testes during aging might be expected to also preserve the function and prevent pathology of testes during aging in humans.

Although not examined in the present study, it is reasonable to consider that, in addition to counteracting the aging process, regular exercise might protect the male reproductive system against diseases that involve oxidative stress. It was shown that 4-HNE modified proteins by which oxidative stress is generated in the testes with varicocele (Shiraishi \& Naito 2005). We found that along with the above-mentioned oxidative stress makers, runners' testes had very little amount of 4-HNE levels compared with sedentary animals, which may indicate that running protects against aging-related oxidative stress and oxidative stress-induced lipid peroxidation in the testes. This was also true for protein oxidation as we noticed that protein carbonyl levels, a biomarker of protein oxidation were also significantly less in runners. As oxidative damage is implicated in many age-related diseases, by reducing oxidative stress, exercise may protect the testes against dysfunction and disease during aging.

\section{Declaration of interest}

The authors declare no conflict of interest.

\section{Funding}

This work was supported by the Intramural Research Program of the National Institute on Aging. 


\section{Acknowledgements}

Tissues and serum samples were kindly provided by Alexis M Stranahan. Author contributions: S C, T G S, D H H, J D L, M M and T V A designed and performed the research; S C, T V A, T G S and D H H analyzed data; and $\mathrm{S}$ C and M P M wrote the manuscript.

\section{References}

Aksoy Y, Yapanoglu T, Aksoy H, Demircan B, Oztasan N, Canakci E \& Malkoc I 2006 Effects of endurance training on antioxidant defense mechanisms and lipid peroxidation in testis of rats. Archives of Andrology $\mathbf{5 2}$ 319-323.

Almahbobi G, Papadopoulos V, Carreau S \& Silberzahn P 1988 Age-related morphological and functional changes in the Leydig cells of the horse. Biology of Reproduction 38 653-665.

Banerjee AK, Mandal A, Chanda D \& Chakraborti S 2003 Oxidant, antioxidant and physical exercise. Molecular and Cellular Biochemistry 253 307-312.

Barnes CJ, Covington BWT, Cameron IL \& Lee M 1998 Effect of aging on spontaneous and induced mouse testicular germ cell apoptosis. Aging $\mathbf{1 0}$ 497-501.

Beal MF 2002 Oxidatively modified proteins in aging and disease. Free Radical Biology and Medicine 32 797-803.

Cadenas E \& Davies KJ 2000 Mitochondrial free radical generation, oxidative stress, and aging. Free Radical Biology and Medicine 29 222-230.

Campbell KL, McTiernan A, Li SS, Sorensen BE, Yasui Y, Lampe JW, King IB, Ulrich CM, Rudolph RE, Irwin ML et al. 2007 Effect of a 12-month exercise intervention on the apoptotic regulating proteins $\mathrm{Bax}$ and $\mathrm{Bcl}-2$ in colon crypts: a randomized controlled trial. Cancer Epidemiology, Biomarkers and Prevention 16 1767-1774.

Cao L, Leers-Sucheta S \& Azhar S 2004 Aging alters the functional expression of enzymatic and non-enzymatic anti-oxidant defense systems in testicular rat Leydig cells. Journal of Steroid Biochemistry and Molecular Biology 88 61-67.

Cumming DC, Wheeler GD \& McColl EM 1989 The effects of exercise on reproductive function in men. Sports Medicine 7 1-17.

Drew B \& Leeuwenburgh C 2002 Aging and the role of reactive nitrogen species. Annals of the New York Academy of Sciences 959 66-81.

Dugan SA 2007 Exercise for health and wellness at midlife and beyond: balancing benefits and risks. Physical Medicine and Rehabilitation Clinics of North America 18 555-575 (xi).

Gautam DK, Misro MM, Chaki SP \& Sehgal N $2006 \mathrm{H}_{2} \mathrm{O}_{2}$ at physiological concentrations modulates Leydig cell function inducing oxidative stress and apoptosis. Apoptosis 11 39-46.

Giovannucci EL, Liu Y, Leitzmann MF, Stampfer MJ \& Willett WC 2005 A prospective study of physical activity and incident and fatal prostate cancer. Archives of Internal Medicine 165 1005-1010.

Gosden RG, Richardson DW, Brown N \& Davidson DW 1982 Structure and gametogenic potential of seminiferous tubules in ageing mice. Journal of Reproduction and Fertility 64 127-133.

Griswold MD 1998 The central role of Sertoli cells in spermatogenesis. Seminars in Cell and Developmental Biology 9 411-416.

Hackney AC, Szczepanowska E \& Viru AM 2003 Basal testicular testosterone production in endurance-trained men is suppressed. European Journal of Applied Physiology 89 198-201.

Harman SM, Metter EJ, Tobin JD, Pearson J \& Blackman MR 2001 Longitudinal effects of aging on serum total and free testosterone levels in healthy men. Baltimore Longitudinal Study of Aging. Journal of Clinical Endocrinology and Metabolism 86 724-731.

Horn R, Pastor LM, Moreno E, Calvo A, Canteras M \& Pallares J 1996 Morphological and morphometric study of early changes in the ageing golden hamster testis. Journal of Anatomy 188 109-117.

Howard CV \& Reed MG Ed 2005 Three-Dimensional Measurement in Microscopy. Abingdon: Garland Science/BIOS.

Jackson MJ, Khassaf M, Vasilaki A, McArdle F \& McArdle A 2004 Vitamin E and the oxidative stress of exercise. Annals of the New York Academy of Sciences 1031 158-168.
Ji LL 2007 Antioxidant signaling in skeletal muscle: a brief review. Experimental Gerontology 42 582-593.

Johnson L 1986 Spermatogenesis and aging in the human. Journal of Andrology $7331-354$

Johnson JB, Summer W, Cutler RG, Martin B, Hyun DH, Dixit VD, Pearson M, Nassar M, Telljohann R, Maudsley S et al. 2007 Alternate day calorie restriction improves clinical findings and reduces markers of oxidative stress and inflammation in overweight adults with moderate asthma. Free Radical Biology and Medicine 42 665-674.

Keller JN \& Mattson MP 1998 Roles of lipid peroxidation in modulation of cellular signaling pathways, cell dysfunction, and death in the nervous system. Reviews in the Neurosciences 9 105-116.

Liu M, Liang Y, Chigurupati S, Lathia JD, Pletnikov M, Sun Z, Crow M, Ross CA, Mattson MP \& Rabb H 2008 Acute kidney injury leads to inflammation and functional changes in the brain. Journal of the American Society of Nephrology 19 1360-1370.

Lyras L, Evans PJ, Shaw PJ, Ince PG \& Halliwell B 1996 Oxidative damage and motor neurone disease difficulties in the measurement of protein carbonyls in human brain tissue. Free Radical Research 24 397-406.

Manna I, Jana K \& Samanta PK 2003 Effect of intensive exercise-induced testicular gametogenic and steroidogenic disorders in mature male Wistar strain rats: a correlative approach to oxidative stress. Acta Physiologica Scandinavica 178 33-40.

Marini M, Lapalombella R, Margonato V, Ronchi R, Samaja M, Scapin C, Gorza L, Maraldi T, Carinci P, Ventura C et al. 2007 Mild exercise training, cardioprotection and stress genes profile. European Journal of Applied Physiology 99 503-510.

Matsumoto AM 2002 Andropause: clinical implications of the decline in serum testosterone levels with aging in men. Journals of Gerontology. Series A, Biological Sciences and Medical Sciences 57 M76-M99.

Mattson MP \& Liu D 2002 Energetics and oxidative stress in synaptic plasticity and neurodegenerative disorders. Neuromolecular Medicine 2 215-231.

Monninkhof EM, Elias SG, Vlems FA, van der Tweel I, Schuit AJ, Voskuil DW \& van Leeuwen FE 2007 Physical activity and breast cancer: a systematic review. Epidemiology 18 137-157.

Morrow JD 2006 The isoprostanes - unique products of arachidonate peroxidation: their role as mediators of oxidant stress. Current Pharmacentical Design 12 895-902.

Myers M, Ebling FJ, Nwagwu M, Boulton R, Wadhwa K, Stewart J \& Kerr JB 2005 Atypical development of Sertoli cells and impairment of spermatogenesis in the hypogonadal (hpg) mouse. Journal of Anatomy 207 797-811.

Neaves WB, Johnson L, Porter JC, Parker CR Jr \& Petty CS 1984 Leydig cell numbers, daily sperm production, and serum gonadotropin levels in aging men. Journal of Clinical Endocrinology and Metabolism 59 756-763.

Paniagua R, Martin A, Nistal M \& Amat P 1987 Testicular involution in elderly men: comparison of histologic quantitative studies with hormone patterns. Fertility and Sterility 47 671-679.

Quindry JC, Hamilton KL, French JP, Lee Y, Murlasits Z, Tumer N \& Powers SK 2007 Exercise-induced HSP-72 elevation and cardioprotection against infarct and apoptosis. Journal of Applied Physiology 103 1056-1062.

Resko JA, Malley A, Begley D \& Hess DL 1973 Radioimmunoassay of testosterone during fetal development of the rhesus monkey. Endocrinology 93 156-161.

Sampson N, Untergasser G, Plas E \& Berger P 2007 The ageing male reproductive tract. Journal of Pathology 211 206-218.

Sanz A, Pamplona R \& Barja G 2006 Is the mitochondrial free radical theory of aging intact? Antioxidants and Redox Signaling 8 582-599.

Schulze W \& Schulze C 1981 Multinucleate Sertoli cells in aged human testis. Cell and Tissue Research 217 259-266.

Shiraishi K \& Naito K 2005 Increased expression of Leydig cell haem oxygenase-1 preserves spermatogenesis in varicocele. Human Reproduction $202608-2613$

Slattery ML 2004 Physical activity and colorectal cancer. Sports Medicine 34 239-252.

Snyder PJ 2001 Effects of age on testicular function and consequences of testosterone treatment. Journal of Clinical Endocrinology and Metabolism $\mathbf{8 6}$ 2369-2372. 
Sohal RS \& Weindruch R 1996 Oxidative stress, caloric restriction, and aging. Science 273 59-63.

Starnes JW \& Taylor RP 2007 Exercise-induced cardioprotection: endogenous mechanisms. Medicine and Science in Sports and Exercise 39 1537-1543.

Vermeulen A 1991 Clinical review 24: androgens in the aging male. Journal of Clinical Endocrinology and Metabolism 73 221-224.

Yamashita N, Hoshida S, Otsu K, Asahi M, Kuzuya T \& Hori M 1999 Exercise provides direct biphasic cardioprotection via manganese superoxide dismutase activation. Journal of Experimental Medicine 189 1699-1706.
Yarborough A, Zhang YJ, Hsu TM \& Santella RM 1996 Immunoperoxidase detection of 8-hydroxydeoxyguanosine in aflatoxin B1-treated rat liver and human oral mucosal cells. Cancer Research 56 683-688.

Received in final form 4 July 2008

Accepted 8 July 2008

Made available online as an Accepted Preprint 13 August 2008 